\title{
Location of Bioelectricity Plants in the Madrid Community Based on Triticale Crop: A Multicriteria Methodology
}

\author{
L. Romero, ${ }^{1}$ M. S. Romero, ${ }^{2}$ M. L. Cuadrado, ${ }^{3}$ and J. Fernández ${ }^{4}$ \\ ${ }^{1}$ Escuela Técnica Superior de Ingenieros Industriales, Universidad Nacional de Educación a Distancia (UNED), 28040 Madrid, Spain \\ ${ }^{2}$ Facultad de Ciencias Económicas y Empresariales, Universidad Nacional de Educación a Distancia (UNED), 28040 Madrid, Spain \\ ${ }^{3}$ Escuela Técnica Superior de Ingenieros de Telecomunicación, Universidad Politécnica de Madrid (UPM), 28040 Madrid, Spain \\ ${ }^{4}$ Escuela Técnica Superior de Ingenieros Agrónomos, Universidad Politécnica de Madrid (UPM), 28040 Madrid, Spain
}

Correspondence should be addressed to L. Romero; lromero@ind.uned.es

Received 9 January 2015; Revised 26 February 2015; Accepted 5 March 2015

Academic Editor: Gongnan Xie

Copyright (C) 2015 L. Romero et al. This is an open access article distributed under the Creative Commons Attribution License, which permits unrestricted use, distribution, and reproduction in any medium, provided the original work is properly cited.

\begin{abstract}
This paper presents a work whose objective is, first, to quantify the potential of the triticale biomass existing in each of the agricultural regions in the Madrid Community through a crop simulation model based on regression techniques and multiple correlation. Second, a methodology for defining which area has the best conditions for the installation of electricity plants from biomass has been described and applied. The study used a methodology based on compromise programming in a discrete multicriteria decision method (MDM) context. To make a ranking, the following criteria were taken into account: biomass potential, electric power infrastructure, road networks, protected spaces, and urban nuclei surfaces. The results indicate that, in the case of the Madrid Community, the Campiña region is the most suitable for setting up plants powered by biomass. A minimum of 17,339.9 tons of triticale will be needed to satisfy the requirements of a $2.2 \mathrm{MW}$ power plant. The minimum range of action for obtaining the biomass necessary in Campiña region would be $6.6 \mathrm{~km}$ around the municipality of Algete, based on Geographic Information Systems. The total biomass which could be made available in considering this range in this region would be $18,430.68 \mathrm{t}$.
\end{abstract}

\section{Introduction}

The future of world energy depends on the progressive substitution of fossil fuels for renewable energy. Therefore, the issue of how to achieve an efficient and rational increase as far as possible in that energy is a topic of enormous interest.

The development of renewable energy from biomass, which has received support from the different administrations, is currently being expanded and is feasible from a technical and economic point of view. To be specific, in the Madrid Community, there is a high potential for biomass, related to the agricultural surface available, mainly in the regions in the south of the Community [1].

Although there is a wide range of possibilities of new crops producing biomass, given their tradition in Spain, cereals are some of the most appropriate ones for obtaining biomass for heat or heat and electricity production [2]. All winter cereal species are susceptible to being used in energy production, mainly wheat, barley, triticale, oat, and rye. Although some are more favorable than others for energy use, triticale, oat, and rye are the species with the lowest harvest indexes (grain biomass/total biomass), which makes them more apt for using their integral biomass for producing energy. Of the three, triticale is the species with the best biomass productivity indexes.

Simulation models constitute a tool which makes use of information obtained through previous experiments, and they permit the projection of physical and economic results, taking into account all the factors interacting in a certain environment. Compared to the variability and complexity of the current production systems, simulation models have been presented as an alternative to be employed in future scenarios [3]. The most complex models enable one to carry out a yield sensitivity analysis based on different factors, combining different types of soil, climate, cultivation, and management. Most of the model applications are related to management aspects such as fertilization or irrigation strategies, sowing dates, or crops with a different cycle, which have to be assessed in accordance with a historical series of climate data. 
A regression analysis is a statistical technique for the modeling and investigation of the relationship between two or more variables, and it has been used for a reasonable amount of time for the estimation of the production of different crops $[4,5]$. A simple linear regression expresses the relationship between a dependent and an independent variable in terms of the slope and the intersection of the line which best fits the variables, whereas, in the multiple regression, the possible relationship between several independent variables and another dependent variable is studied. For the estimation of cereal yield, the dependent variable would be the biomass production and the independent ones the climatological data (such as temperature, radiation, or precipitation), soil, fertilization, irrigation, and so forth variables.

Pertaining to the establishment of bioelectricity plants based on triticale biomass in the Madrid Community, a multicriteria decision method has been used to determine the best region. The best location in this area has been established using Geographic Information Systems, which were acquired by inputting some geographical restrictions.

Geographic Information Systems (GIS) have been used to determine what there is in a certain location, find suitable land for a specific purpose, establish the temporal differences in a particular place, and carry out statistical distributions and modeling to make an analysis of the territory using decisionmaking processes [6, 7]. Among the latter, multicriteria decision methods (MDMs) are powerful mathematical tools, which can be used as models for the evaluation and combination of variables. They are based on the analysis, discussion, and ranking of alternatives with the aim of offering solutions to problems [8]. The alternatives analyzed by the MDMs can be infinite when they are defined by a set of feasible solutions of a continuous mathematical nature (continuous multicriteria methods), or finite, normally in not a very high number (discrete multicriteria methods).

This work has studied, by means of GIS and MDM, the potential production of triticale biomass in the Madrid Community and the possibility of using it for the electricity production in each of the six agricultural regions.

\section{Methodology}

The purpose of this work was, first, to quantify the triticale biomass potential in each of the six agricultural regions of the Madrid Community and, second, to define which of them offers the best conditions for the installation of electricity plants powered by biomass. It was also aimed at determining the most suitable location for a bioelectricity plant in the area with best conditions.

A work methodology, whose flow diagram is shown in Figure 1, has been designed to cover the following stages.

(1) Determining the surface potentially usable for the triticale crop.

(2) Generating a biomass production model for the triticale crop.

(3) Quantifying the available potential yield of triticale biomass.

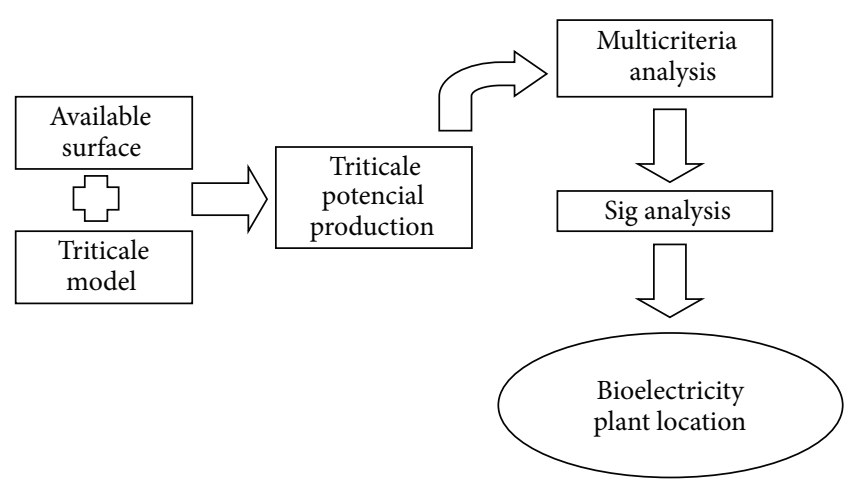

FIGURE 1: Flow diagram for the position of biomass plants.

(4) Making a multicriteria analysis to define the region with the best conditions for the installation of bioelectricity plants.

(5) Performing a GIS analysis for the determination of the most suitable location for a bioelectricity plant in the region considered.

2.1. Surface Available. It was aimed at assessing the agricultural surface which could potentially be devoted to cultivating triticale for the production of biomass in each of the regions in the study area, establishing a scenario which represents a percentage of the employment of the rainfed fallow surface.

2.2. Model for Triticale Biomass Production. The assessment of the potential production of triticale biomass in the agricultural regions available in each municipality was carried out through a production model or function which relates the climate variables and the known production of cereal crops. This model represents the expected potential production in each region.

To set up this model, regression and multiple correlation techniques which quantify the statistical association between two or more variables were used.

To develop the biomass production model, first a grain production model was generated on the basis of trials or estimations carried out in the Madrid Community, and, subsequently, the biomass/grain ratio was calculated in accordance with a pilot experiment carried out in the ETSIA Practice Fields.

2.2.1. Grain Production Model. To develop this model, a relationship between the mean grain production data from the trials and the climatological variables measured in the area of each trial (mean temperature and total rainfall in the period) was established. Only climatological variables were employed due to triticale having a small root system, and to considering that fallow land is apt for growing cereals.

Values from trials on triticale grain yield used were compiled in "Encuesta de Superficies y Rendimientos" (ESYRCE) of MAGRAMA during the 2008-2009, 2009-2010, 2010-2011, and 2011-2012 cropping seasons.

The climate data for setting up the model were obtained at the "Agencia Estatal de Meteorología" (AEMET). The data 
were mean temperature and total rainfall from October to June during the corresponding cropping years from the weather stations with data closest to the sampled trials of triticale grain yield.

For the particular case of this work, multiple regression logarithmic curves for the development of the models (with the aim of controlling the production and so that it did not shoot up for extreme climatological values) were employed; the equations were considered to have a good correlation when the determination index $\left(R^{2}\right)$ was found in the interval between 0.8 and 1 [9]. The tool used for the regression obtainment was Microsoft Excel 2010.

First, it was necessary to normalize the climatological data in order to be able to enter dimensionless values in the model. As a base for the normalization of the temperature the value 9.9 was taken, and for the rainfall, 496.7. Those values corresponded to the municipality average in the Madrid Community for a series of 30 years (1971-2000) from October to June and were supplied by the AEMET.

Average estimation data grouped per cropping season and weather station were used. To enter the data in the model, it was considered that it was the rainfall rather than the temperature that exerted a double influence.

2.2.2. Obtainment of Biomass/Grain Ratio. To perform the experiment, four varieties of triticale were selected: Amarillo, Trujillo, Collegial, and Bienvenu.

It was aimed at obtaining the total biomass/grain of the different triticale varieties submitted to two different rainfall regimes. For this purpose, 24 containers were prepared, 12 for each type of irrigation, and, within each irrigation group, 3 replications for each variety were carried out.

The experiment was performed in containers measuring $60 \times 42 \times 40(\mathrm{~cm})$ so that the surface of each one was $0.252 \mathrm{~m}^{2}$.

\subsection{Potential Triticale Biomass Production. Starting from} the surface available and the triticale biomass production model, it was possible to quantify the biomass potential at a municipality level in the study area based on the triticale crop.

The electrical output that is desired at each plant is 2.2 MW. According to the Natural Electric SA company, using a natural circulation boiler tube, with a mobile grille of alternative movement, a working pressure in the boiler of 42 bars and a maximum continuous steam production of $11,000 \mathrm{~kg} / \mathrm{h}$, and a twin turbine running with a double radial stage and an axial stage and, finally, an electric generator of $2.630 \mathrm{kVA}$, $6.6 \mathrm{kV}$, and IP 44R, the expected performance could be 8,000 hours per year with an efficiency that varies between 21 and $22 \%$. Therefore, the gross electricity production will be $17,600 \mathrm{MWh}$ yearly (the net production will be somewhat less due to auxiliary charges).

The amount of biomass required will depend on the lowest calorific power (LCP) upon arrival at the plant, which will be measured by its moisture content. The biomass should not be placed in the boiler at over 30\% moisture, although, for this work, only dry triticale biomass is considered. Efficiency ranges from 21 to $22 \%$, so the intermediate value $(21.5 \%)$ has been used for the calculations.
The procedure for calculating the biomass necessary $(M)$ was the following ( $M$ being expressed in tons of m.s., LCP in $\mathrm{kcal} / \mathrm{kg}$ and $P$ in Mwh):

$$
\mathrm{P}=\mathrm{LCP} * \mathrm{M} * \frac{0.215}{860} \longrightarrow \mathrm{M}=17600 * \frac{860}{\mathrm{LCP}} * 0.215 .
$$

In the case of dry triticale biomass, a LCP of $4,060 \mathrm{kcal} / \mathrm{kg}$ was considered [10], so that a minimum of 17,339.9 tons will be needed to satisfy the requirements of each of the power plants.

Only the potentially usable biomass from those municipalities whose centroids are included within the established radius of action will be computed. This is because, for its collection, some storage centers adjacent to the urban nuclei of each of them have been planned. The optimal area for the location of the power plants will be the surface within the suitable areas corresponding to the municipality, whose surroundings will be considered as being their range of action.

2.4. Multicriteria Analysis for the Determination of the Region with the Best Conditions for Bioelectricity. In this stage, a multicriteria analysis will be carried out to determine which region enjoys the best conditions for the installation of bioelectricity plants. For this purpose, a group of $n$ regions was considered and each one evaluated according to $m$ acceptability criteria.

The proposed methodology, based on compromise programming in a discrete multicriteria decision-making context, will involve defining an index of acceptability that aggregates the different acceptability criteria attached to each of the considered agrarian regions. Therefore, the n potential alternatives can be ranked according to their overall acceptability.

It should be noted that, in order for the proposed methodology to be of interest, the aggregate acceptability index should satisfy some common-sense properties, such as the following.

(a) Since the number of agrarian regions and indicators of acceptability in many real world situations can be high, the index calculation procedure should be simple.

(b) The interpretation of the index should be clear and straightforward.

(c) The index should represent a good balance between very wide-ranking criteria.

The first step in determining the aggregated acceptability indicator, given that the acceptability indicators are mostly measured in different units, is to normalize the different evaluations reached by the districts considered. A simple and pragmatic normalisation procedure successfully used in another context [11] is as follows:

$$
\bar{P}_{i j}=\frac{P_{i j}-P_{* j}}{P_{j}^{*}-P_{* j}}, \quad i=1,2, \ldots, n, j=1,2, \ldots, m,
$$

where $P_{i j}=$ evaluation reached by the $i$ th agricultural area $(i=1,2, \ldots, n)$ when it is evaluated with respect to the $j$ th 
acceptability criterion $(j=1,2, \ldots, m) . P_{j}^{*}=$ ideal value of the $j$ th acceptability criterion. This value is given by the maximum evaluation if the criterion is of the "more is better" type (e.g., the biomass potential) or by the minimum evaluation if the criterion is of the "less is better" type (e.g., the protected natural spaces surface). $P_{* j}=$ the anti-ideal value of the $j$ th acceptability criterion. This value is given by the minimum evaluation if the criterion is of the "more is better" type or by the maximum evaluation if the criterion is of the "less is better" type. $\bar{P}_{i j}=$ normalized evaluation reached by the $i$ th region when it is evaluated with respect to the $j$ th acceptability criterion.

It is worth noting that, with the normalization used, the normalized values are dimensionless, positive, and limited between 0 (when the district reaches the worst value) and 1 (when the district reaches the best value), respectively. Also, for this normalization system, $\mathbf{1}$ and $\mathbf{0}$ are elements of $\mathbf{R}^{\mathbf{m}}$, namely, $m$ components vectors defined by

$$
\mathbf{1}=(1,1, \ldots, 1)^{T}, \quad \mathbf{0}=(0,0, \ldots, 0)^{T},
$$

where the ideal vector is equal to $\mathbf{1}$ and the anti-ideal one is equal to $\mathbf{0}$, which is very convenient for understanding any possible aggregation.

Computing the vector of the acceptability criteria weights $w=\left(w_{1}, w_{2}, \ldots, w_{m}\right)^{T} \in \mathbf{R}^{\mathbf{m}}$. It is proposed to obtain this by applying columns' aggregation method, to the squared matrix $A$ : $\left(a_{i j}\right)$, of the order $m$, positive $\left(a_{i j} \in \mathbf{R} / a_{i j}>0\right)$, of diagonal elements one $\left(a_{i i}=1\right)$, reciprocal $\left(a_{i j}, a_{j i}=1\right)$ and generally inconsistent $\left(a_{i j} \neq a_{i k}, a_{k j}\right)$, which is obtained when comparing pairwise, employing the Saaty numerical scale [12-17], the $m$ acceptability criteria considered.

Taking this into account and considering the algebraic properties of the matrices of the pairwise comparison to be "consistent," it is proposed to obtain an estimate of the weights vector $\mathbf{w}$ by applying the following calculation scheme $[18,19]$.

(a) Normalization of the pairwise comparison matrix $A$ dividing each of its components by the sum of the elements of the column to which it belongs. By doing this, matrix $A^{N}$ is obtained, in which the sum of the elements of each column is equal to one.

(b) Calculation of the components of the vector which approximates the weights vector $\mathbf{w}$ as the arithmetical mean of the elements situated in each row of the normalized matrix $A^{N}$.

(c) Validation of the consistency, through the so-called consistency ratio (R.C.).

To carry out the latter, taking into account that, if the pairwise comparison matrix $A$ of order $m$ of positive diagonal elements one and reciprocal is not consistent, it holds that its dominant eigenvalue $\lambda_{\max } \geq m$ is equal if, and only if, $A$ is consistent, a coefficient (C.I. $=$ consistency index) will be defined given by

$$
\text { C.I. }=\frac{\lambda_{\max }-m}{m-1},
$$

where

$$
\lambda_{\max }=\frac{1}{k} \sum_{j=1}^{k} \frac{j \text { th component of } A \mathbf{w} \text { vector }}{j \text { th component of } \mathbf{w} \text { vector }}
$$

which will be employed to measure the degree of consistency of the value judgments emitted by the decision-maker when constructing the pairwise comparison matrix of the acceptability criteria. The nearer to zero the C.I. value, the better the global consistency of the matrix; in fact, if the matrix is consistent, it will be verified that C.I. $=0$.

Calibrating the coefficient C.I. making use of the coefficient C.I.A. (= random consistency index), obtained by simulation with random matrices of the same order, gives the so-called consistency ratio:

$$
\text { R.C. }=\frac{\text { C.I. }}{\text { C.I.A }} .
$$

Verifying that, if R.C. $\leq 0.1$, the degree of consistency of the pairwise comparison matrix is acceptable, but if R.C. $>0.1$, some serious inconsistencies may arise and it is recommendable to revise the value judgments emitted by the decision-maker when constructing the matrix.

Knowing the values $\bar{P}_{i j}$ and $w_{j}, i=1,2, \ldots, n, j=1,2$, $\ldots, m$, to establish the aggregate acceptability index $I_{i}^{A}, i=1$, $2, \ldots, n$, of each of the $n$ agrarian regions considered, it is necessary to define in $\mathbf{R}^{\mathbf{m}}$ a function "distance between the vector of normalized values" reached by the $i$ th region $\overline{\mathbf{P}}_{i j}=$ $\left(\bar{P}_{i 1}, \bar{P}_{i 2}, \ldots, \bar{P}_{i m}\right)^{T}$ and the ideal vector $\mathbf{1}=(1,1, \ldots, 1)^{T}$. With this aim in mind, the following distance functions are introduced:

$$
\begin{aligned}
L_{p}\left(\mathbf{1}, \overline{\mathbf{P}}_{i j}\right) & =\left[\sum_{j=1}^{m} w_{j}^{p}\left(1-\bar{P}_{i j}\right)^{p}\right]^{1 / p}, \quad 1 \leq p<\infty \\
& =\max \left[\begin{array}{c}
w_{j}(1-j \leq m \\
\left.1 \leq \bar{P}_{i j}\right)
\end{array}\right], \quad p=\infty .
\end{aligned}
$$

The first expression defined adds the normalized and weighted proximity degrees of all the acceptability criteria considered at their ideal value, proving that, as metric $p$ increases, more importance is given to the larger deviations, whereas the second expression is limited to finding the maximum normalized and weighted degree of proximity of all the acceptability criteria at its ideal value.

Specifying metric $p$ in (7), the aggregate acceptability index value for the $i$ th agrarian region will be given by the following expression:

$$
I_{i}^{A}=L_{p}\left(1, \overline{\mathbf{P}}_{i j}\right) .
$$

Having calculated the aggregate acceptability indicator of the areas considered to make their hierarchical ranking, the following axiom of choice will be used: "The alternatives nearest to the ideal alternative are preferred to the alternatives furthest away from it." 
This conductual axiom, introduced in the decision theory of Zelany in 1974 [20], is a behavior postulate firmly rooted in psychology, which permits taking into account the preferences of the decision-making center and ranks hierarchically the different possible alternatives.

The application of Zeleny axiom to the whole of the aggregate acceptability index $I_{i}^{A}, i=1,2, \ldots, n$, obtained by applying (8) to each of the agrarian regions considered, will permit the obtainment of their hierarchical selection order. Acting in this way, the first district in the hierarchy will be the one with the lowest aggregate acceptability indicator (i.e., the district which minimizes the distance between the vectors $\overline{\mathbf{P}}_{i j}$ and $\mathbf{1}$ defined previously).

To calculate in a computationally simple way $I_{i}^{A}$, defined by the generally nonlinear formula (8) for any value of the metric $p$, it is proposed to use the following convex linear combination $[21,22]$ :

$$
\left.\left.(1-\lambda) L_{p}\left(\mathbf{1}, \overline{\mathbf{P}}_{i j}\right)\right]_{p=\infty}+\lambda L_{p}\left(\mathbf{1}, \overline{\mathbf{P}}_{i j}\right)\right]_{p=1}
$$

for values of $\lambda \in[0.1]$.

Specifying the value of $\lambda$ in (9) and considering (7) give

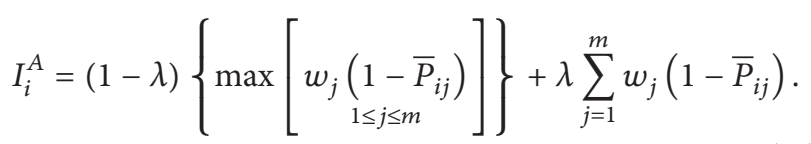

In expression (10), analogically to $p$ in (8), $\lambda$ is a control parameter, which not only permits one to obtain different hierarchical rankings of the districts but, most importantly, enables the manifestation of different preference structures from the decision-making center with respect to their ranking.

"The most acceptable region" for $\lambda=1$ is the one with the best aggregate characteristics, namely, the district which maximizes the weighted sum of the accomplishment of the acceptability criteria. This additive solution is "the best" in aggregate terms but it may be unacceptable in practical ones. Actually, a large aggregate average may be compatible with a poor evaluation of any one of the criteria, which may make the region in question ineligible in selection terms.

"The most acceptable region" for $\lambda=0$ is the one for which the deviation of the criterion most displaced from its ideal value is minimized. Therefore, the region which maximizes the equilibrium between the achievements of the different acceptability criteria considered is "the best one."

Taking into account these considerations, in the application of the methodology proposed, it is recommended to give $\lambda$ a value belonging to the open interval $(0,1)$, which obtains good aggregate and balanced characteristics for the region in carrying out all the acceptability criteria considered.

2.5. GIS Analysis for the Localization of the Agroindustry. The development of the last stage of the methodology will determine the optimal site for a small biomass power plant $(2.2 \mathrm{MW})$ in each of the agrarian regions making up the study area, provided that the necessary biomass potential exists there.
This process, carried out by using Geographic Information Systems, consists of two steps.

(1) A diagnosis of the suitable areas for the location of bioelectricity plants based on a series of preestablished criteria.

(2) The determination of the municipality within each agrarian region around which a low range of action is necessary for the obtainment of the total biomass required to supply a $2.2 \mathrm{MW}$ plant.

\section{Application of the Proposal Methodology to the Madrid Community}

3.1. Potentially Available Surface. It is to calculate the potentially usable surface, a scenario in which $50 \%$ of the rainfed fallow land is considered to triticale cultivation.

3.2. Setting-Up of the Triticale Biomass Production Model. This means the generation of a model resulting from the combination of the biomass/grain ratio and a grain yield model based on climatological data.

3.2.1. Grain Production Model. This consists basically of correlating rainfall and temperature data with trial values of known triticale grain yields.

For its development, mean values of triticale grain yield were used. These are compiled in "Encuesta sobre Superficies y Rendimientos" (ESYRCE) of the MAGRAMA during the cropping seasons 2008-2009, 2009-2010, 2010-2011 and 2011-2012, and rainfall and temperature data from different weather stations located in the Madrid Community and which have been provided by "Agencia Estatal de Meteorología” (AEMET).

Table 1 details the grain yield estimated in $\mathrm{kg} / \mathrm{ha}$ and the location of the trials.

To obtain the models, multiple regression logarithmic curves were used and it was established that, for the equations to be valid, the determination index $\left(R^{2}\right)$, which shows the percentage of the variability of the data, had to be higher than 0.8 in each case.

After analyzing the triticale grain yield data with respect to its normalized climate variables, the yield model in tons per hectare was obtained:

$$
\begin{aligned}
& \text { Triticale grain yield }(\mathrm{t} / \mathrm{ha}) \\
& \quad=2.4495 * \ln (\mathrm{TN}+2 * \mathrm{PN})+2.6103
\end{aligned}
$$

The determination index $\left(R^{2}\right)$ for grain yield model was of 0.9804 , so that the characteristics desired were fulfilled.

To calculate the triticale grain yield at a municipality level, the normalized average of a climatological series of 30 years (1971-2000) provided by the AEMET was used.

3.2.2. Biomass/Grain Ratio. To calculate the biomass production of the triticale varieties, two of the three replications of each variety for each type of irrigation were employed. This harvest was made when the grain was in a semihard state. 
TABLE 1: Average grain yield in $\mathrm{kg} / \mathrm{ha}$ of triticale trials carried out in the Madrid Community associated with the closest weather stations and mean temperature $\left(T^{a}\right)$ in ${ }^{\circ} \mathrm{C}$ and accumulated rainfall $(P)$ in $\mathrm{mm}$ from Octuber to June in each of the seasons considered. Source: MAGRAMA/AEMET.

\begin{tabular}{|c|c|c|c|c|}
\hline Season & Average yield (kg/ha) & Weather station & $T^{a}\left({ }^{\circ} \mathrm{C}\right)$ & $P(\mathrm{~mm})$ \\
\hline 2008-2009 & 1,941 & MADRID/GETAFE & 12.4 & 263.8 \\
\hline 2009-2010 & 2,350 & VALDEMORILLO & 10.7 & 403.7 \\
\hline $2009-2010$ & 2,689 & MADRID/GETAFE & 12.3 & 454.9 \\
\hline 2009-2010 & 2,600 & VILLAMANRIQUE TAJO (BODEGONES) & 11.4 & 455.3 \\
\hline 2010-2011 & 2,100 & VILLAMANRIQUE TAJO (BODEGONES) & 11.1 & 311.1 \\
\hline 2010-2011 & 2,250 & MADtRID/GETAFE & 12.6 & 337.6 \\
\hline 2010-2011 & 2,385 & VILLAVICIOSA DE ODON & 11.4 & 402 \\
\hline
\end{tabular}

TABLE 2: Average yields of grain and dry biomass $\left(\mathrm{g} / \mathrm{m}^{2}\right)$ and biomass/grain ratio of each triticale variety for irrigation of $348.8 \mathrm{~mm} /$ year.

\begin{tabular}{lccc}
\hline Variety & $\begin{array}{c}\text { Total grain } \\
\left(\mathrm{g} / \mathrm{m}^{2}\right)\end{array}$ & $\begin{array}{c}\text { Dry biomass } \\
\left(\mathrm{g} / \mathrm{m}^{2}\right)\end{array}$ & $\begin{array}{c}\text { Biomass/grain } \\
\text { ratio }\end{array}$ \\
\hline Amarillo & 232.88 & 510.00 & 2.19 \\
Trujillo & 197.07 & 500.55 & 2.54 \\
Colegial & 140.10 & 361.45 & 2.58 \\
Bienvenu & 267.94 & 533.20 & 1.99 \\
Average & $\mathbf{2 0 9 . 5 0}$ & $\mathbf{4 7 6 . 3 0}$ & $\mathbf{2 . 2 7}$ \\
\hline
\end{tabular}

TABLE 3: Average yields of grain and dry biomass $\left(\mathrm{g} / \mathrm{m}^{2}\right)$ and biomass/grain ratio of each variety of triticale for irrigation of $462.1 \mathrm{~mm} /$ year.

\begin{tabular}{lccc}
\hline Variety & $\begin{array}{c}\text { Total grain } \\
\left(\mathrm{g} / \mathrm{m}^{2}\right)\end{array}$ & $\begin{array}{c}\text { Dry biomass } \\
\left(\mathrm{g} / \mathrm{m}^{2}\right)\end{array}$ & $\begin{array}{c}\text { Biomass/grain } \\
\text { ratio }\end{array}$ \\
\hline Amarillo & 230.08 & 756.95 & 3.29 \\
Trujillo & 266.31 & 774.95 & 2.91 \\
Colegial & 153.83 & 481.50 & 3.13 \\
Bienvenu & 330.37 & 842.45 & 2.55 \\
Average & $\mathbf{2 4 5 . 1 5}$ & $\mathbf{7 1 3 . 9 6}$ & $\mathbf{2 . 9 1}$ \\
\hline
\end{tabular}

With the third replication of each triticale variety for each irrigation type, a second harvest was carried out at the end of the dry grain state. The aim of this second harvest was to determine the grain yield and establish the biomass/grain ratio of each of the varieties. The results for each type of irrigation are indicated in Tables 2 and 3.

The average biomass/grain ratio for triticale was of $\mathbf{2 . 5 9 5}$. According to the trials carried out in the Madrid Community by the Agroenergy Group of Polytechnic University of Madrid in the municipalities of Quijorna and Daganzo de Arriba and in the practice fields of the ETSIA during the cropping seasons 2009-2010 and 2010-2011, collected in the PSE On Cultivos [23], the average biomass/grain ratio for the triticale varieties was of 2.633. Thus, the value obtained in the experiment, despite only having been developed during one cropping season, was considered as being acceptable for entering in the triticale biomass production model.
3.2.3. Biomass Production Model. By associating the average biomass/grain ratio obtained in the experiment with the grain yield model, the model for biomass production in tons per hectare of triticale (where $\mathrm{TN}=$ normalized mean temperature and NP = normalized accumulated precipitation) can be determined:

Triticale biomass production ( $\mathrm{t} / \mathrm{ha})$

$$
=2.595 *[2.4495 * \ln (\mathrm{TN}+2 * \mathrm{PN})+2.6103] \text {. }
$$

3.3. Potential Triticale Biomass Production. Starting from the surface available and the triticale biomass production model, biomass potential at a municipality level in the Madrid Community can be quantified on the basis of the triticale crop.

It is planned to store the biomass in collection centers adjacent to the urban nuclei of each municipality, from where it can all be transported faster and more efficiently.

3.4. Multicriteria Analysis for the Determination of the Agrarian Region with the Best Conditions for Installing the Power Plants. It is aimed at defining the agrarian region with the best characteristics for the installation of electricity plants powered by biomass. For this purpose, the different alternatives and criteria have to be defined.

Alternatives: these will be the six agrarian regions of the Madrid Community (Área Metropolitana, Campiña, Guadarrama, Lozoya-Somosierra, Sur Occidental, and Vegas), shown in Figure 2.

Criteria, described from greater to lesser importance, 3 of which are favorable (the maximum value is of interest), 4 are limiting (the minimum value is awarded), and one is exclusionary [24]:

(i) Biomass Potential $\left(\mathrm{Tm} / \mathrm{Km}^{2}\right)$. This is the most important criterion. Imposing limitations whereby a plant must be situated near the extraction area of the raw material mean that, similarly, in turn, both the surfaces where it is possible to place the facilities and that potential will increase. Furthermore, a greater potential would permit the power generation of a hypothetical plant to be enhanced. This is a favorable criterion.

(ii) Electricity Infrastructure (Number of Substations $/ \mathrm{Km}^{2}$ ). The characteristics of the electricity network are fundamental 


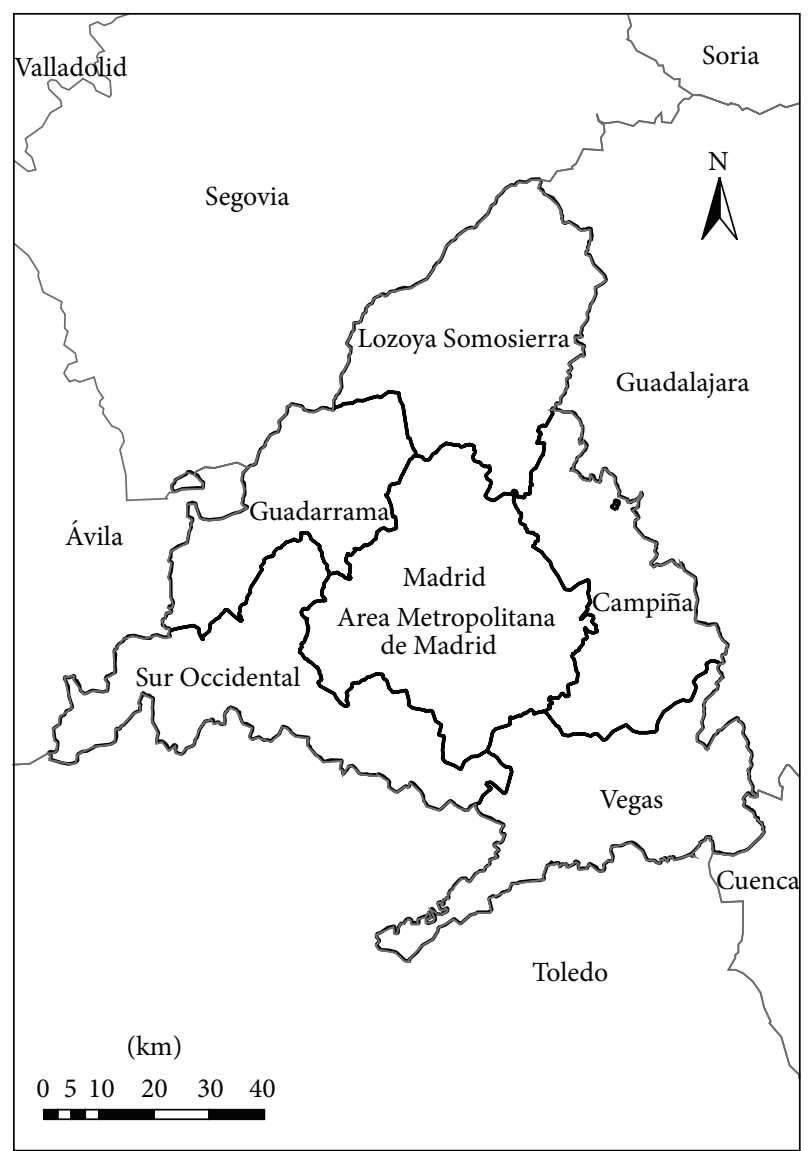

FIGURE 2: Location of the agrarian regions of the Madrid Community.

when distributing the power generated by the plant. The better the electricity network available, the lower the costs of investing in infrastructure for that distribution will be, which facilitates the siting of the plant. This is a favorable criterion.

(iii) Road Network $\left(\mathrm{Km} / \mathrm{Km}^{2}\right)$. A good communications infrastructure signifies a reduction in the costs of the energy and increases the surface accessible for the collection of the raw material, thus enabling the use of a larger amount. This is a favorable criterion.

(iv) Water Availability. This criterion will not, in principle, establish dominance relationships between the different alternatives since the water required by this type of installation practically functions in a closed circuit, so that a greater availability than the minimum required is of no advantage. This criterion will therefore generally be exclusionary: if any of these alternatives does not present a feasible way of obtaining the necessary volume of water it will automatically be eliminated. After analyzing this fact in each of the agrarian regions, none of them have been excluded for that reason.

(v) Protected Natural Spaces (\% of Protected Surface). Another way of introducing the environmental component into the study is by penalizing those alternatives which are of an important environmental wealth, so that the impact of installations such as those described will be as low as possible. This criterion is a limiting one.

(vi) Urban Nuclei (\% of Urban Surface). The surface occupied by urban nuclei will not be considered as being apt for the installation of biomass power plants. This is a limiting criterion.

(vii) Plants Installed (Number of Stations $/ \mathrm{Km}^{2}$ ). The presence of some type of plant powered by biomass in any of the agricultural regions could diminish the amount of biofuel available for a newly built one. This circumstance may be used to penalize the regions with any initiative already in force. However, if there are no such installations, this criterion will not establish any dominance relationships. This would be a limiting criterion.

(viii) Slope of the Land. To set up the plant, the area must not have a very steep slope. This is a limiting criterion.

Since the multicriteria analysis will be made in agricultural regions, it is reasonable to predict that in each of them there is some land with a suitable slope for the installation of the plant, so that the slope criterion will not be taken into account. Neither the water availability criterion nor that of the plants installed will establish any dominance relationships, so that finally 5 criteria will be used to carry out the study:

(i) biomass potential (BIOMASS),

(ii) number of substations per agrarian district (SUBSTATIONS),

(iii) road network (ROADS),

(iv) \% natural protected spaces (NPS),

(v) \% urban nuclei surface (NUCLEI).

To apply the methodology proposed, each of the criteria has to be quantified in the regions with the aim of enabling the ranking of the different alternatives. To carry out this process, digital mapping treatment through Geographic Information Systems will be resorted to.

3.5. GIS Analysis for the Location of a Bioelectricity Plant in the Best Agrarian Region of Madrid Community. To determine the best site for a small (2.2 MW) biomass plant in the region with best assessment, a process is followed in two stages.

(1) Diagnosis of suitable areas in the Community of Madrid for the setting-up of biomass plants based on the following conditions.

(a) Presence of an electric power substation at a radius of under $10 \mathrm{~km}$.

(b) Impossibility of installing a biomass power plant at a radius of under $2 \mathrm{~km}$ around the different urban nuclei.

(c) Impossibility of installing it at a radius of under $2 \mathrm{~km}$ around the protected natural spaces existing in the Madrid Community.

(d) The distance of the plant from water courses must be at an interval of 1 to $5 \mathrm{~km}$. 
TABLE 4: Values $\left(P_{i j}\right)$ per unit of surface of the acceptability criteria reached by each of the agrarian regions of the Madrid Community.

\begin{tabular}{lccccc}
\hline Alternatives & Biomass $\left(\mathrm{t} / \mathrm{km}^{2}\right)$ & Subst. $\left(\mathrm{ud} / \mathrm{km}^{2}\right)$ & Roads $\left(\mathrm{km} / \mathrm{km}^{2}\right)$ & $\mathrm{NPS}\left(\mathrm{km}^{2} / \mathrm{km}^{2}\right)$ & $\mathrm{Nuclei}\left(\mathrm{km}^{2} / \mathrm{km}^{2}\right)$ \\
\hline Área Metropolitana & 29.219 & 0.116 & 1.046 & 0.228 & 0.145 \\
Campiña & 78.637 & 0.020 & 0.701 & 0.027 & 0.033 \\
Guadarrama & 0.970 & 0.005 & 0.856 & 0.362 & 0.049 \\
Lozoya Somosierra & 8.795 & 0.003 & 0.619 & 0.075 & 0.022 \\
Sur Occidental & 50.295 & 0.032 & 0.641 & 0.114 & 0.036 \\
Vegas & 57.324 & 0.014 & 0.590 & 0.016 \\
\hline
\end{tabular}

TABLE 5: Normalized values of the acceptability criteria $\left(\bar{P}_{i j}\right)$ reached by each of the agrarian regions in the Madrid Community.

\begin{tabular}{lccccc}
\hline Alternatives & Biomass & Subst. & Roads & NPS & Nuclei \\
\hline $\begin{array}{l}\text { Área } \\
\text { Metropolitana }\end{array}$ & 0.364 & 1.000 & 1.000 & 0.399 & 0.000 \\
Campiña & 1.000 & 0.157 & 0.244 & 1.000 & 0.864 \\
Guadarrama & 0.000 & 0.022 & 0.584 & 0.000 & 0.739 \\
Lozoya & 0.101 & 0.000 & 0.064 & 0.511 & 0.954 \\
Somosierra & 0.635 & 0.255 & 0.111 & 0.855 & 0.840 \\
Sur Occidental & 0.726 & 0.098 & 0.000 & 0.740 & 1.000 \\
Vegas & & & & &
\end{tabular}

(e) The plant's distance from the road network cannot be over $1.5 \mathrm{~km}$.

(2) Determination of the lowest range of action for obtaining the total biomass necessary to supply a plant of 2.2 MW in the region considered.

Once suitable areas for installing the bioelectricity plants in the Madrid Community have been localized, the municipality around which a lower range of action is needed to obtain all types of the biomass necessary to supply the plant should be determined in the region considered.

Only the potentially usable biomass from those municipalities whose centroids are included in the range of action will be computed, since for its collection storage centers adjacent to the urban nuclei of each of them are planned.

The optimal area for the location of the plants will be the surface within the suitable areas corresponding to the municipality around which the range of action will be fixed.

\section{Results}

4.1. Hierarchization of the Regions. Applying the methodology proposed, the following results are obtained.

The six agricultural regions will be ranked according to the value reached by their aggregate acceptability indicator. With regard to the potential biomass criterion, values associated with the utilization of $50 \%$ of the rainfed fallow land for each of the regions are employed.

Table 4 shows the evaluation $P_{i j}, i=1,2, \ldots, 6, j=1,2$, $\ldots, 5$, reached by each of the regions when they are evaluated following each of the five acceptability criteria considered.

Table 5 shows the normalized evaluation $\bar{P}_{i j}, i=1,2$, $\ldots, 6, j=1,2, \ldots, 5$, reached by each of the six regions when they are evaluated according to each of the five acceptability criteria considered. It should be remembered that, in this context, zero denotes "the worst" value (the anti-ideal one) whereas 1 denotes the "best" value (the ideal one).

Also, it is assumed that matrix $A$ (of positive elements, diagonals one, reciprocal and inconsistent) of the pairwise comparison of the acceptability criteria considered is

$$
\left(\begin{array}{ccccc}
1 & 3 & 4 & 5 & 6 \\
\frac{1}{3} & 1 & 2 & 3 & 4 \\
\frac{1}{4} & \frac{1}{2} & 1 & 2 & 3 \\
\frac{1}{5} & \frac{1}{3} & \frac{1}{2} & 1 & 2 \\
\frac{1}{6} & \frac{1}{4} & \frac{1}{3} & \frac{1}{2} & 1
\end{array}\right)
$$

whereas the normalized matrix $A^{N}$ is

$$
\left(\begin{array}{lllll}
.5128 & .5902 & .5106 & .4348 & .3750 \\
.1709 & .1967 & .2553 & .2609 & .2500 \\
.1282 & .0984 & .1277 & .1739 & .1875 \\
.1026 & .0656 & .0638 & .0870 & .1250 \\
.0855 & .0492 & .0426 & .0435 & .0625
\end{array}\right) \text {. }
$$

Calculating the average of each row of matrix $A^{N}$, an estimation is obtained of the weights vector $\mathbf{w}$ whose components are as follows:

(i) $w_{1}(\mathrm{BI})=0.4847$,

(ii) $w_{2}(\mathrm{SB})=0.2268$,

(iii) $w_{3}(\mathrm{RO})=0.1431$,

(iv) $w_{4}(\mathrm{NPS})=0.0888$,

(v) $w_{5}(\mathrm{NU})=0.0566$.

The consistency index of matrix $A$ is 0.0248 , while the random consistency index of a matrix of order 5 is 1.115 , so that it holds that the consistency ratio

$$
\text { R.C. }=\frac{\text { C.I. }}{\text { C.I.A }}=\frac{0.0248}{1.115}=0.0222<0,1 \text {. }
$$

With these data, by applying the Zeleny axiom to the set of values $I_{i}^{A}, i=1,2, \ldots, 6$, obtained from (10) for 
TABLE 6: Values of the aggregate acceptability index $\left(I_{i}^{A}\right)$ for $\lambda=0.5$ reached for each of the regions and their hierarchical rating.

\begin{tabular}{lcc}
\hline Alternatives & $I_{i}^{A}$ & Order \\
\hline Campiña & 0.2493 & 1 \\
Sur Occidental & 0.3320 & 2 \\
Vegas & 0.3541 & 3 \\
Área Metropolitana & 0.3634 & 4 \\
Lozoya Somosierra & 0.6393 & 5 \\
Guadarrama & 0.6771 & 6 \\
\hline
\end{tabular}

different values of $\lambda$, the different rankings of the considered alternatives showing different preference structures from the decision-making center can be accomplished.

In this study, the calculation of the aggregate acceptability index and the hierarchical ordering of the regions was done for $\lambda=0.5$ (Table 6), which is the average value between the maximum aggregate evaluation $(\lambda=1)$ and the maximum balanced evaluation $(\lambda=0)$.

4.2. Location of Plants by GIS. Figure 3 shows the final surface available in the agrarian regions of the Madrid Community for the location of plants powered by biomass, based on the criteria established.

In this section, the results of the biomass plant installation in the region with the best evaluation in the multicriteria analysis are given: Campiña.

The minimum range of action for obtaining the necessary biomass would be $6.6 \mathrm{~km}$ around the municipality of Algete and would comprise the centroids of the municipalities of Cobeña, Daganzo de Arriba, Fuente el Saz de Jarama, Valdeolmos-Alalpardo, and Algete itself. The potentially usable biomass using $50 \%$ of the rainfed fallow land in the Campiña region would be allocated as follows (Figure 4):

(i) Algete: $3,937.50 \mathrm{t}$.

(ii) Cobeña: 2,694.93 t.

(iii) Daganzo de Arriba: 4,515.26 t.

(iv) Fuente el Saz de Jarama: 4,137.57 t.

(v) Valdeolmos-Alalpardo: 3,145.41 t.

The total biomass which could be made available in considering this range would therefore be $18,430.68 \mathrm{t}$.

\section{Conclusions}

The triticale productivity model developed in this work is a good example of the yields obtained in the trials carried out in different areas of the Madrid Community.

On making a hierarchical ranking of the agrarian regions of the Madrid Community for $\lambda=0.5$ (seeking a balance between the maximum equilibrated and aggregate evaluation), the Campiña region is the most suitable for the installation of electricity plants powered by triticale biomass on the basis of the criteria of biomass potential, electricity infrastructure, road networks, protected spaces, and urban
Suitable areas for the location of power bioelectricity plants

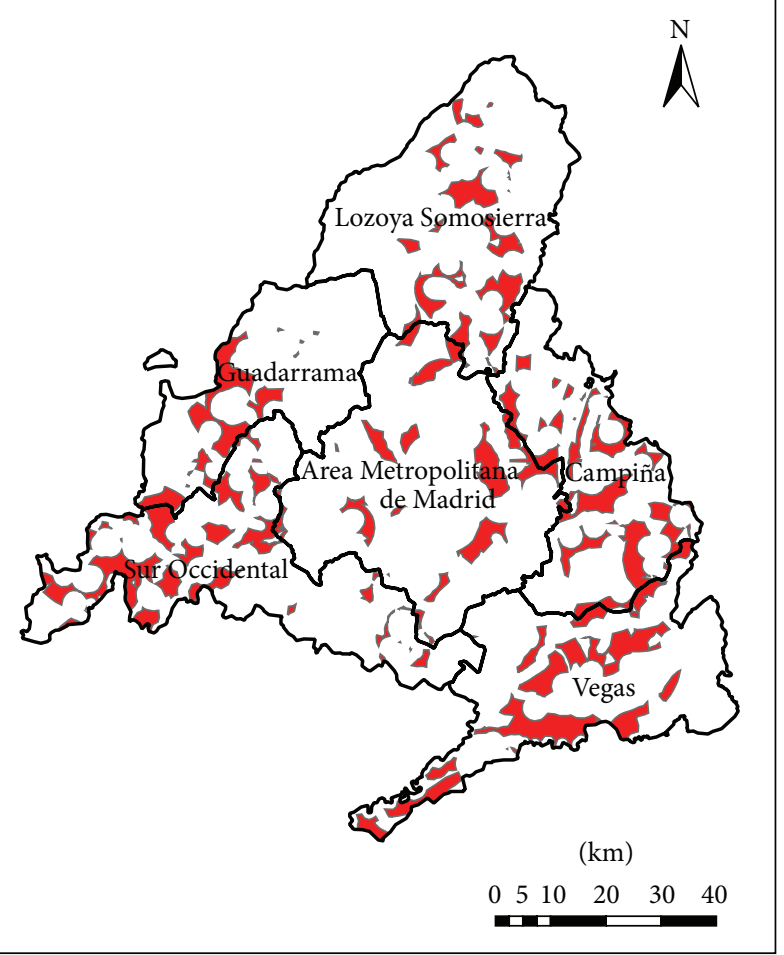

FIgURE 3: Suitable areas for the location of bioelectricity plants in the Madrid Community.

nuclei surface. Lozoya-Somosierra and Guadarrama are the worst considered.

The methodology developed could be perfectly applied to other areas at the same latitude and with similar climatology.

To satisfy the requirements of a bioelectricity plant of $2.2 \mathrm{MW}$, a minimum of $17,339.9 \mathrm{t}$ of triticale would be necessary. The results obtained when determining the most suitable location of this type of plant in Campiña region are municipality of Algete and a range of action of $6.6 \mathrm{~km}$ for the obtainment of necessary biomass $(18,430.68 \mathrm{t})$.

If a larger power plant had been chosen, the action radius would increase considerably and this would lead to logistical problems and also a fee reduction per kWh produced.

\section{Web Pages}

Consider the following:

(i) Agencia Estatal de Meteorología http://www.aemet .es/es/portada.

(ii) Aplicación SIGA. Ministerio de Medio Ambiente y Medio Rural y Marino http://www.mapa.es/es/sig/ pags/siga/intro.htm.

(iii) Centro de Investigaciones energéticas, medioambientales y tecnológicas http://www.ciemat.es/.

(iv) European Commission http://ec.europa.eu/research/ leaflets/energy/es/04.html. 

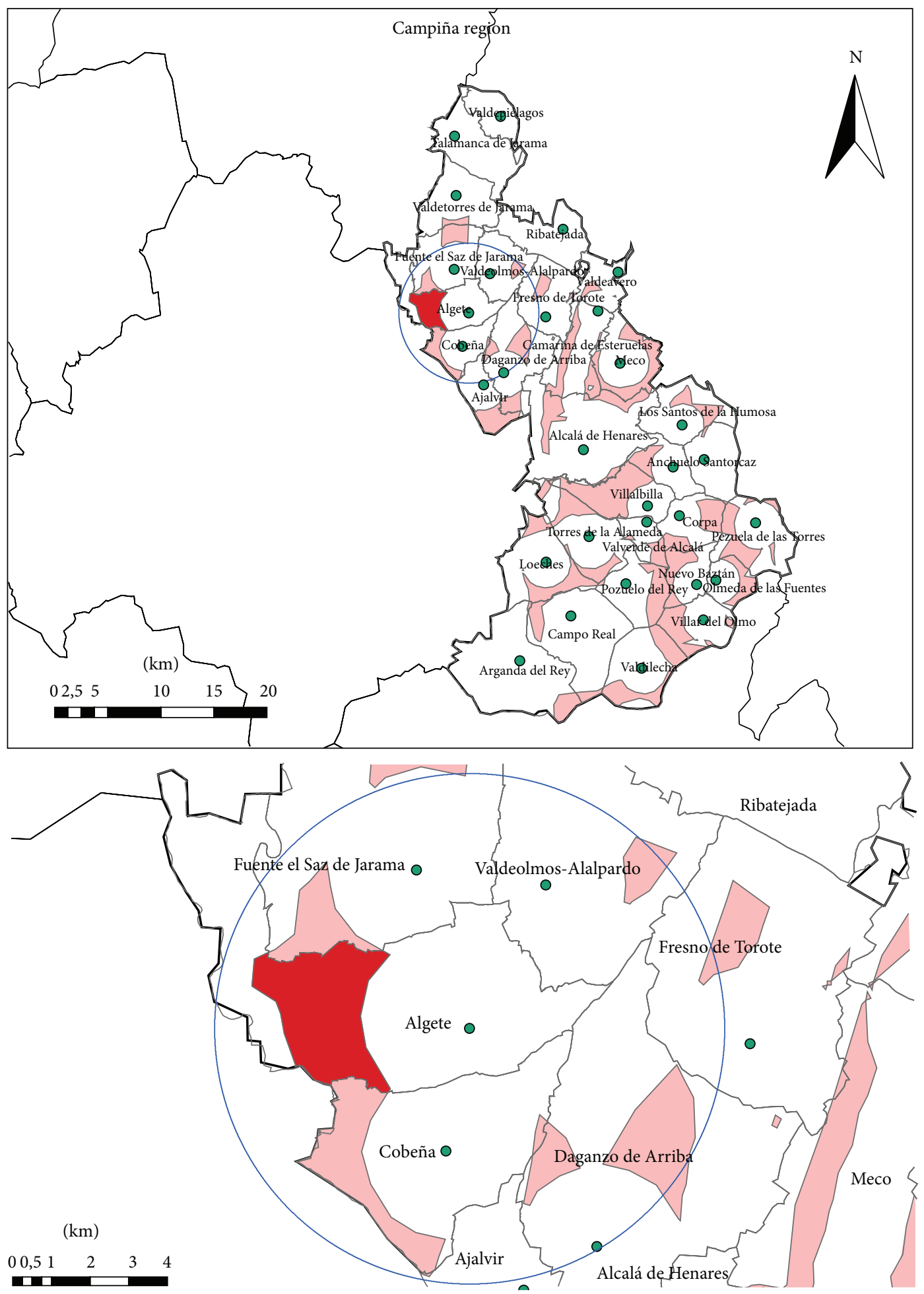

FIGURE 4: Minimum range of action for the obtainment of necessary biomass using $50 \%$ of the rainfed fallow surface and the optimal area for the location of a bioelectricity plant of $2.2 \mathrm{MW}$ in the Campiña region. 
(v) Instituto para la Diversificación y Ahorro de la Energía http://www.idae.es/.

(vi) On Cultivos http://www.oncultivos.es/.

\section{Conflict of Interests}

The authors declare that there is no conflict of interests regarding the publication of this paper.

\section{Acknowledgments}

The authors would like to thank the Agroenergy Group of UPM and the Construction and Fabrication Engineering Department of UNED the support provided for the preparation of this work.

\section{References}

[1] Fundación de la Energía de la Comunidad de Madrid, Balance Energético de la Comunidad de Madrid en el año 2010, 2012.

[2] Instituto para la Diversificación y Ahorro de la Energía (IDAE), Biomasa: Cultivos energéticos, IDAE, 2007.

[3] A. Rocha, F. E. Bert, M. M. Skansi et al., "Pronóstico de rendimiento de los cultivos de granos en la región pampeana a través del uso de modelos de simulación agronómica," Modelo de Simulación Ceres, UBA, Buenos Aires, Argentina, 2012.

[4] N. Picard, L. Saint-André, and M. Henry, Manual de construcción de ecuaciones alométricas para estimar el volumen y la biomasa de los árboles, CIRAD/FAO, 2012.

[5] M. H. Kutner, C. Nachtsheim, and J. Neter, Applied Linear Regression Models, Lavoisier, 4th edition, 2004.

[6] M. Álvarez, "Últimos avances en Sistemas de Información Geográfica," in Ciclo de Videoconferencias del Gabinete de Teleeducación, UPM, 2004.

[7] E. Martínez, M. Álvarez, Á. Arquero, and M. Romero, “Apoyo a la selección de emplazamientos óptimos de edificios. Localización de un edificio mediante el Proceso Analítico Jerárquico (AHP)," Informes de la Construcción, vol. 62, no. 519, pp. 35-45, 2010.

[8] C. Romero, Análisis de Las Decisiones Multicriterio, Isdefe, 1996.

[9] D. C. Montgomery, E. A. Peck, and G. G. Vining, Introduction to Linear Regression Analysis, Wiley Series in Probability and Statistics, John Wiley \& Sons, 5th edition, 2012.

[10] J. Fernández, Energía de la biomasa. Energías renovables para todos, Iberdrola, 2008.

[11] L. Díaz-Balteiro and C. Romero, "In search of a natural systems sustainability index," Ecological Economics, vol. 49, no. 3, pp. 401-405, 2004.

[12] T. L. Saaty, The Analytic Hierarchy Process, McGraw-Hill International, New York, NY, USA, 1980.

[13] T. L. Saaty and L. G. Vargas, "Comparison of eigenvalue, logarithmic least squares and least squares methods in estimating ratios," Mathematical Modelling, vol. 5, no. 5, pp. 309-324, 1984.

[14] T. L. Saaty, "Axiomatic foundation of the analytic hierarchy process," Management Science, vol. 32, no. 7, pp. 841-855, 1986.

[15] T. L. Saaty, "Highlights and critical points in the theory and application of the analytic hierarchy process," European Journal of Operational Research, vol. 74, no. 3, pp. 426-447, 1994.
[16] T. L. Saaty and G. Hu, "Ranking by eigenvector versus other methods in the analytic hierarchy process," Applied Mathematics Letters, vol. 11, no. 4, pp. 121-125, 1998.

[17] T. L. Saaty, "Decision-making with the AHP: why is the principal eigenvector necessary," European Journal of Operational Research, vol. 145, no. 1, pp. 85-91, 2003.

[18] J. González-Pachón and C. Romero, "Analysis of pairwise comparison matrices," in Wiley Enciclopedia of Operations Research and Management Science, pp. 1-9, 2011.

[19] J. González-Pachón, L. Diaz-Balteiro, and C. Romero, "How to combine inconsistent ordinal and cardinal preferences: a satisficing modelling approach," Computers \& Industrial Engineering, vol. 67, no. 1, pp. 168-172, 2014.

[20] M. Zelany, "A concept of compromise solutions and the method of the displaced ideal," Computers and Operations Research, vol. 1, no. 3-4, pp. 479-496, 1974.

[21] F. J. André and C. Romero, “Computing compromise solutions: on the connections between compromise programming and composite programming," Applied Mathematics and Computation, vol. 195, no. 1, pp. 1-10, 2008.

[22] M. A. Martín, M. L. Cuadrado, and C. Romero, "Computing efficient financial strategies: an extended compromise programming approach," Applied Mathematics and Computation, vol. 217, no. 19, pp. 7831-7837, 2011.

[23] PSE OnCultivos, Proyecto Singular y Estratégico para el desarrollo, demostración y evaluación de la viabilidad de la producción de energía en España a partir de biomasa de cultivos energéticos, CIEMAT, 2011.

[24] F. Hidalgo, Análisis multicriterio para la óptima ubicación de una central de energía a partir de biomasa en Andalucía, Universidad Pablo de Olavide, Sevilla, Spain, 2003. 


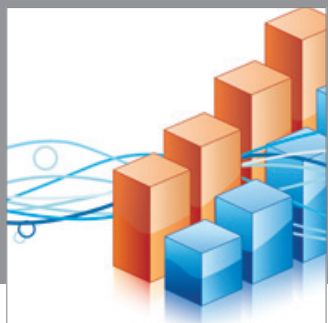

Advances in

Operations Research

mansans

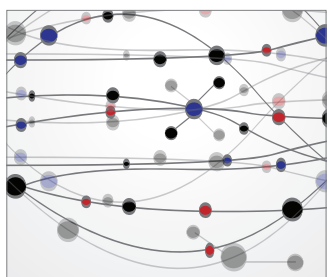

The Scientific World Journal
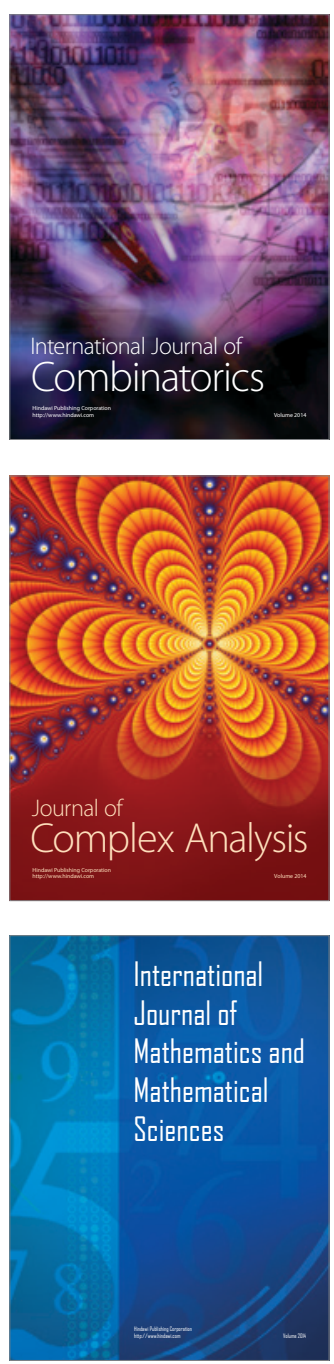
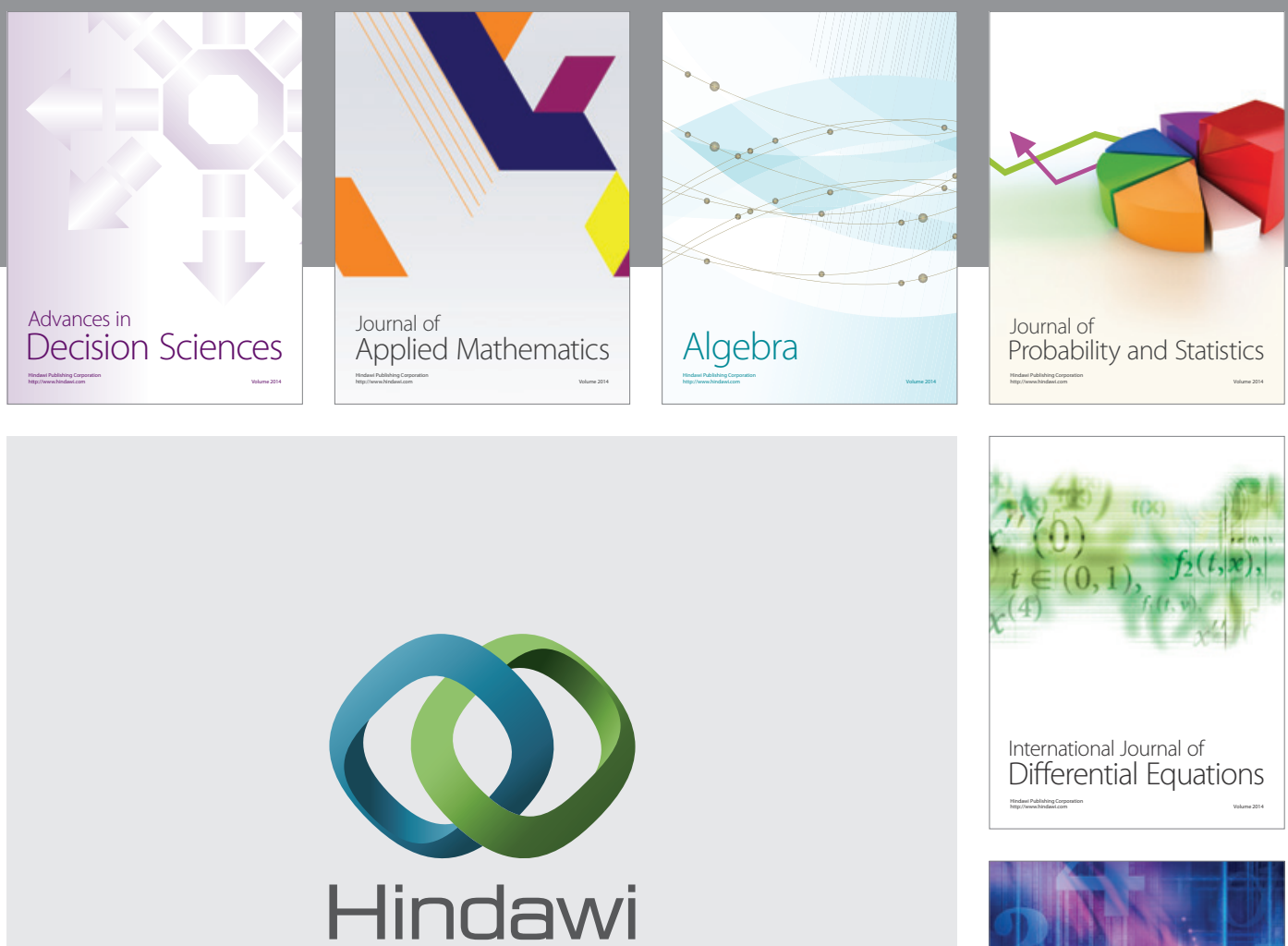

Submit your manuscripts at http://www.hindawi.com
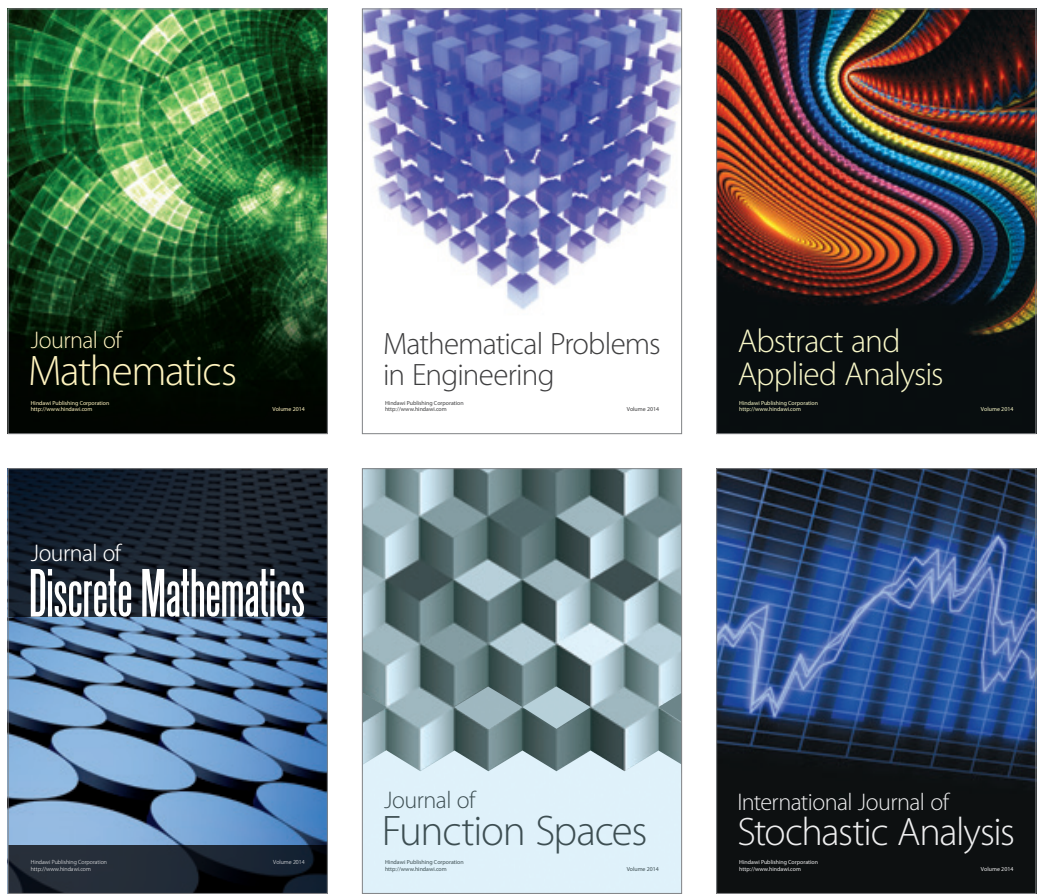

Journal of

Function Spaces

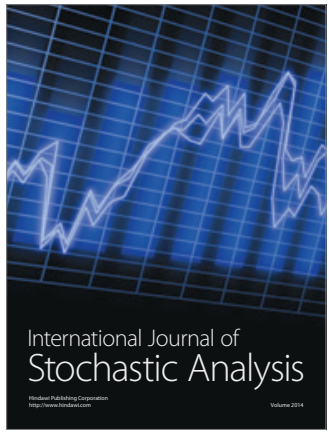

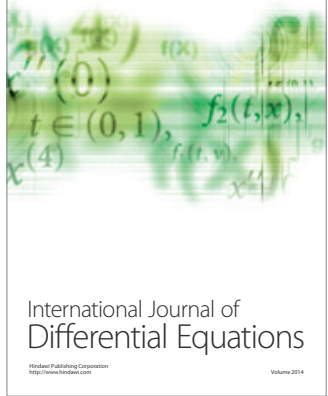
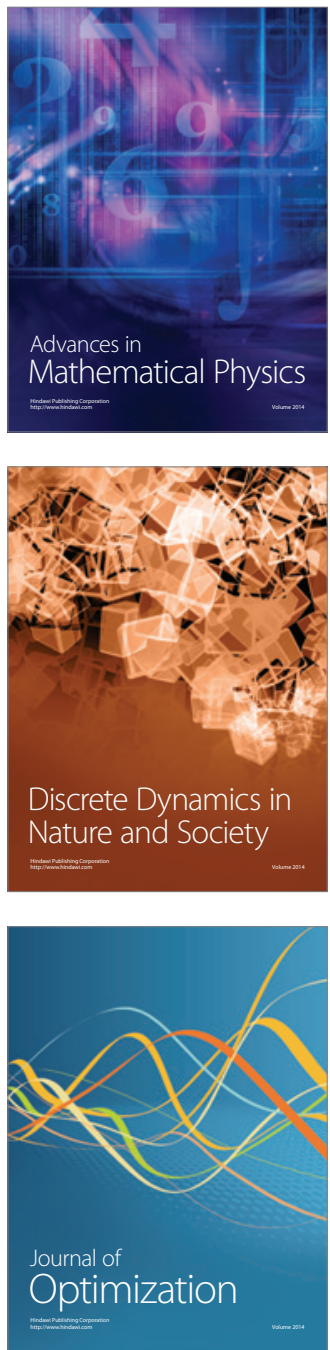